\title{
Stage IV Laryngeal Cancer AJCC v6
}

National Cancer Institute

\section{Source}

National Cancer Institute. Stage IV Laryngeal Cancer A/CC v6. NCI Thesaurus. Code C6868.

Stage IV includes: IVA: (T4a, N0, M0); (T4a, N1, M0); (T1, N2, M0); (T2, N2, M0); (T3, N2, M0); (T4a, N2, M0); IVB: (T 4b, Any N, M0); (Any T, N3, M0); IVC: (Any T, Any N, M1). T4: (Suprag lottis) T4a: Tumor invades through the thyroid cartilage and/or invades tissues beyond the larynx (e.g., trachea, soft tissues of neck including deep extrinsic muscle of the tongue, strap muscles, thyroid, or esophagus). T4b: Tumor invades prevertebral space, encases carotid artery, or invades mediastinal structures. (Glottis) T4a: Tumor invades through the thyroid cartilage and/or invades tissues beyond the larynx (e.g., trachea, soft tissues of neck including deep extrinsic muscles of the tongue, strap muscles, thyroid, or esophagus). T4b: Tumor invades prevertebral space, encases carotid artery, or invades mediastinal structures. (Subglottis) T4a: Tumor invades cricoid or thyroid cartilage and/or invades tissues beyond the larynx (e.g., trachea, soft tissues of neck including deep extrinsic muscles of the tongue, strap muscles, thyroid, or esophagus). T4b: T umor invades prevertebral space, encases carotid artery, or invades mediastinal structures. N2: Metastasis in a single ipsilateral lymph node, more than $3 \mathrm{~cm}$ but not more than $6 \mathrm{~cm}$ in greatest dimension, or in multiple ipsilateral lymph nodes, none more than $6 \mathrm{~cm}$ in greatest dimension, or in bilateral or contralateral lymph nodes, none more than $6 \mathrm{~cm}$ in greatest dimension. N2a: Metastasis in a single ipsilateral lymph node more than $3 \mathrm{~cm}$ but not more than $6 \mathrm{~cm}$ in greatest dimension. N2b: Metastasis in multiple ipsilateral lymph nodes, none more than $6 \mathrm{~cm}$ in greatest dimension. N2c: Metastasis in bilateral or contralateral lymph nodes, none more than $6 \mathrm{~cm}$ in greatest dimension. N3: Metastasis in a lymph node more than $6 \mathrm{~cm}$ in greatest dimension. M1: Distant metastasis. (AJCC 6th ed.) 